\title{
Younger age of patients with myocardial infarction is associated with a higher number of relatives with a history of premature atherosclerosis
}

\author{
Michał Ambroziak* (10, Katarzyna Niewczas-Wieprzowska, Agnieszka Maicka and Andrzej Budaj
}

\begin{abstract}
Background: Premature coronary artery disease is one of the most pressing global issues in modern cardiology. The aim of the study was to investigate the role of family history of premature cardiovascular disease (CVD) in patients aged $<50$ years with myocardial infarction (MI) compared to that in patients aged $\geq 50$ years with $\mathrm{Ml}$ and to that in young people without $\mathrm{Ml}$ (no-Ml $<50)$.

Methods: The studied group ( $\mathrm{Ml}<50)$ consisted of 240 patients aged 26-49 years with Ml. The control groups consisted of 240 patients $(\mathrm{Ml} \geq 50)$ with $\mathrm{Ml}$ aged $50-92$ years and 240 healthy people aged 30-49 years without a history of $\mathrm{Ml}(\mathrm{no}-\mathrm{Ml}<50)$.

Results: There were statistically significant differences between the $\mathrm{Ml}<50$ and $\mathrm{Ml} \geq 50$ and no-Ml $<50$ groups regarding the family history of premature $\mathrm{MI} /$ ischaemic stroke and the percentage of patients with $\geq 2$ relatives affected $(10.8,2.9$, and $3.7 \%$, respectively; $p<0.0001)$. There was a statistically significant difference in the patient age at the first MI occurrence among patients without a family history of premature CVD, those with 1 affected relative, and those with $\geq 2$ affected first-degree relatives (56.6, 48.6 and 41.8 years, respectively) as well as those with affected first- and second-degree relatives (56.5, 50.7 and 47.0 years, respectively).

Conclusions: A younger age of patients with myocardial infarction is associated with a higher number of relatives with a history of premature Ml/ischaemic stroke. Thus, the family history of premature atherosclerosis involving not only first- but also second-degree relatives seems to be a valuable factor in CVD risk evaluation in young people.
\end{abstract}

Keywords: Myocardial infarction at a young age, Premature coronary artery disease, CVD family history

\section{Background}

Coronary artery disease (CAD), according to a report of the American Heart Association, remains the leading cause of cardiovascular disease (CVD) deaths [1]. Regarding this, premature $\mathrm{CAD}$ seems to be one of the most pressing global issues in this area.

\footnotetext{
* Correspondence: madaba@op.pl

The study has been presented at the recent EuroPrevent Congress (2019). Department of Cardiology, Centre of Postgraduate Medical Education, Grochowski Hospital, Grenadierów 51/59, 04-730 Warsaw, Poland
}

Data regarding the prevalence of myocardial infarction (MI) in young people differ according to assumptive cutoff age and study population. The percentage of patients aged < 35 years who underwent cardiac catheterization due to MI was determined to be $2 \%$ [2]. Recently published data reported that $10 \%$ of patients with MI, STelevation MI (STEMI), non-ST-elevation MI (NSTEMI), and unstable angina (UA) were $\leq 40$ years of age [3]. Patients aged $<40$ years represented $1.2 \%$ of all patients with MI in a Polish study [4]. When a cut-off age of 45

(c) The Author(s). 2020 Open Access This article is licensed under a Creative Commons Attribution 4.0 International License, which permits use, sharing, adaptation, distribution and reproduction in any medium or format, as long as you give appropriate credit to the original author(s) and the source, provide a link to the Creative Commons licence, and indicate if changes were made. The images or other third party material in this article are included in the article's Creative Commons licence, unless indicated otherwise in a credit line to the material. If material is not included in the article's Creative Commons licence and your intended use is not permitted by statutory regulation or exceeds the permitted use, you will need to obtain permission directly from the copyright holder. To view a copy of this licence, visit http://creativecommons.org/licenses/by/4.0/ The Creative Commons Public Domain Dedication waiver (http://creativecommons.org/publicdomain/zero/1.0/) applies to the data made available in this article, unless otherwise stated in a credit line to the data. 
was established, the percentage of patients increased to $3.2 \%$ [5]. The percentage of adults aged $<55$ years with MI within participants of the Global Registry of Acute Coronary Events (GRACE) was 23 [6]. In one of the recently published meta-analyses, the cut-off age for a young age of acute coronary syndrome (ACS) was established at 50 [7].

Family history appears to be one of the most important and significant risk factors in young patients with MI. It covers inherited genetic as well as environmental risk factors (diet, lifestyle, smoking). A recently published Polish study (the MAGNETIC Project) revealed that young adults with a family history of premature CAD presented unfavourable dietary patterns, which suggested a possible continuity of familial lifestyle across generations [8].

A family history of premature CV events is defined as MI or ischaemic stroke in first-degree relatives at age < 55 years in men and $<65$ years in women $[9,10]$. The INTERHEART study indicated that parental history of CAD was a risk factor independent of environmental, cultural, behavioural, classic, and genetic conditions [11]. Furthermore, the age of onset of disease in parents and whether one or both parents are affected are valuable information and provide an assessment of individual risk of MI. Nevertheless, data regarding the role of a history of premature $\mathrm{CV}$ events in family members other than parents are scarce.

The aim of the study was to analyse risk factors for MI at a young age, particularly the role of a family history of CVD. Regarding various of cut-off ages for young MI among the literature, we used the age of 50 years in this study. We investigated the family history of premature $\mathrm{MI} /$ ischaemic stroke in patients with $\mathrm{MI}$ at age $<50$ compared to that in patients with $\mathrm{MI}$ at age $\geq 50$ and to that in young people without MI (no-MI $<50$ ). We assessed correlations between the number of relatives affected and the age of MI patients, including not only parents but also other family members, such as siblings, grandmothers, grandfathers, children and siblings of parents.

\section{Methods}

\section{Patients}

The investigated population included 720 persons, some of whom were participants in the previously published study [12].

The studied group consisted of 240 young patients aged $<50$ years (mean age $43.5, \mathrm{SD} \pm 5.0$; range $26-49$ ) admitted to the Department of Cardiology, Centre of Postgraduate Medical Education, Grochowski Hospital (Warsaw) with first-episode MI diagnosed based on ST changes in ECG, including STEMI (ST-elevation MI) as well as NSTEMI (non-ST-elevation MI), serum troponin levels and clinical manifestation. The group $(\mathrm{MI}<50$ group) consisted of 188 men and 52 women (78.3 and $21.7 \%$, respectively).

The data from the studied group were compared to those of the control group ( $\mathrm{MI} \geq 50$ group), including 240 patients admitted to our department due to the first-episode MI, aged $\geq 50$ years, range 50-92 (mean 65.9 years, $\mathrm{SD} \pm 12.6$ ), including 152 men and 88 women (63.3 and $36.7 \%$, respectively).

All patients with MI (groups $\mathrm{MI}<50$ and $\mathrm{MI} \geq 50$ ) had coronary artery atherosclerosis confirmed by angiography. In both groups of MI patients, the exclusion criteria were previous MI, MI type 2 without atherosclerotic changes in coronary arteries and a lack of consent for participation in the study.

The other control group consisted of young people without MI, aged, similar to the studied group $<50$ years (mean 43.2 years, SD \pm 5.0 , range from 30 to 49 years), without a history of CAD. This group $($ no-MI $<50)$ included 137 men and 103 women (57.1 and 42.9\%, respectively). These participants were recruited from the Regional Blood Centre and a general practitioner outpatient clinic. The exclusion criteria for the healthy control group were MI or angiographic features of CAD and a lack of consent for participation in the study.

We collected detailed information regarding family history of premature CVD (MI/ischaemic stroke in men aged $<55$ and in women aged $<65$ ), body mass index (BMI), smoking, hypertension, diabetes mellitus (DM) and depression from all participants of the study (together 720 persons). Data regarding family history were collected during the interview with a clinician, a medical doctor. The detailed questions were asked, including the specific diagnosis of heart disease in a family member, the exact patient age of an event occurrence and specific information regarding kinship. In case of doubt regarding the family history, the patient had an opportunity to contact the family member to obtain precise information, if available. If the information provided by the patient was not clear or certain, it was not included in the analysis.

Data regarding risk factors and comorbidities were collected during the interview with a clinician, a medical doctor, at the first meeting at baseline. When there were doubts regarding previous diagnoses, the patient was asked to provide medical documentation.

Hypertension was defined, according to ESH/ESC (European Society of Hypertension, European Society of Cardiology) guidelines, as values $\geq 140 \mathrm{mmHg}$ for systolic blood pressure (SBP) and/or $\geq 90 \mathrm{mmHg}$ for diastolic blood pressure (DBP), based on repeated blood pressure measurements, medical history and ongoing bloodpressure-lowering treatment [13]. DM was assessed according to WHO and ADA (American Diabetes 
Association) guidelines based on at least two glucose measurements of fasting plasma glucose $\geq 126 \mathrm{mg} / \mathrm{dl}$ or $\geq$ $200 \mathrm{mg} / \mathrm{dl}$ in oral glucose tolerance test measurements, based on medical history and hypoglycaemic ongoing treatment [14]. Smoking refers to both current smoking and former smoking. Occasional smoking in the distant past ( $>10$ years until baseline) or a total number of cigarettes smoked per life less than 100 were excluded from this category, and these patients were treated as nonsmokers.

The investigation conforms to the principles outlined in the Declaration of Helsinki. The study protocol was approved by the Ethical Committee of the Centre of Postgraduate Medical Education. The participants gave written informed consent for participation in the study.

\section{Biochemical analyses}

The blood for all biochemical analyses, including glucose, total cholesterol, HDL and LDL cholesterol and triglyceride (TG) plasma concentrations, was taken in the early morning after admission to the hospital. Analyses were determined from fasting blood samples by standard enzymatic methods using COBAS INTEGRA 800 reagents and equipment (Roche Diagnostics Gmbh, Manheim, GE).

\section{Statistical analyses}

Continuous data are presented as arithmetic means and SDs for normally distributed variables and medians and interquartile ranges (25-75th) for skewed distributions. Differences between means were examined with t-tests. Before using the analysis logarithmic transformations were used for triglicerides and glucose. The differences in binary proportions between groups were analysed using the chi2 test of independence or Fisher's exact test. Cochran-Mantel-Haenszel modified ridit scores for categorical variables with $>2$ categories were used. All hypotheses were two-tailed with a type I error rate of 0.05 . All calculations were performed with SAS software version 9.4 (SAS Institute Inc., Cary, NC, USA).

\section{Results}

\section{Clinical and metabolic characteristics of the studied groups}

There was a statistically significant higher prevalence of smoking $(86.4 \%$ vs $64.3 \%, p<0.001)$, BMI $\left(28.6 \mathrm{~kg} / \mathrm{m}^{2}\right.$ vs $\left.27.6 \mathrm{~kg} / \mathrm{m}^{2}, p=0.012\right)$, total cholesterol $(210.0 \mathrm{mg} \%$ vs $197.7 \mathrm{mg} \%, p=0.006)$ and TG levels $(145.5 \mathrm{mg} \%$ vs $1113.0 \mathrm{mg} \%, p<0.001)$ in the $\mathrm{MI}<50$ group than in the $\mathrm{MI} \geq 50$ group. Prevalence of hypertension $(55.2 \%$ vs $68.1 \%, \mathrm{p}<0.001)$, DM (15.9\% vs $35.7 \%, \mathrm{p}<0.001)$, HDL cholesterol $(41.5 \mathrm{mg} \%$ vs $47.6 \mathrm{mg} \%, \mathrm{p}<0.001)$ and fasting glucose $(99.0 \mathrm{mg} \%$ vs $105.4 \mathrm{mg} \%, p=0.002)$ levels were significantly lower in the $\mathrm{MI}<50$ group than in the $\mathrm{MI} \geq$ 50 group (Table 1 ).

Statistically significant differences between the $\mathrm{MI}<50$ group and the no-MI $<50$ group included smoking (86.4\% vs $43.1 \%$, respectively, $p<0.001)$, BMI $(28.6 \mathrm{~kg} /$ $\mathrm{m}^{2}$ vs $\left.27.0 \mathrm{~kg} / \mathrm{m}^{2}, p<0.001\right)$, prevalence of hypertension $(55.2 \%$ vs $29.2 \%, p<0.001), \mathrm{DM}(15.9 \%$ vs $0.8 \%, p<$ $0.001)$ and depression ( $8.4 \%$ vs $3.3 \%, p=0.018)$ as well as LDL cholesterol (132.4 mg\% vs $123.3 \mathrm{mg} \%, p=0.049$ ), HDL ( $41.5 \mathrm{mg} \%$ vs $54.1 \mathrm{mg} \%$, p < 0.001), TG $(145.5 \mathrm{mg} \%$ vs $120.0 \mathrm{mg} \%, \mathrm{p}<0.001)$ and glucose $(99.0 \mathrm{mg} \%$ vs 93.0 $\mathrm{mg} \%, \mathrm{p}<0.001)$ levels.

There were 16.7, 26.2 and $0.8 \%$ participants on statin treatment at baseline in the $\mathrm{MI}<50, \mathrm{MI} \geq 50$ and no$\mathrm{MI}<50$ groups, respectively. There were no individuals using or addicted to cocaine, HIV infected or affected by other severe communicable diseases neither within the study group of $\mathrm{MI}<50$ nor both control groups of $\mathrm{MI} \geq$ 50 and no-MI $<50$ individuals.

\section{Socioeconomic characteristics of the studied groups}

There were significant differences between the $\mathrm{MI}<50$ group and the $\mathrm{MI} \geq 50$ group in the level of education (percentage of people with primary education $5.7 \%$ vs $15.2 \%$ respectively, $p=0.001$ ), the type of job (blue-collar $48.4 \%$ vs $41.3 \%$, respectively, $p<0.001$ ) and marital status (percentage of single people: $18.5 \%$ vs $8.68 \%$ respectively, $p<0.001$ ); Table 2 .

Comparing the $\mathrm{MI}<50$ group and the no- $\mathrm{MI}<50$ group, there were statistically significant differences in the level of education (percentage of people with university degree $22.3 \%$ vs $41.7 \%$, respectively, $p<0.001$ ) and the type of job (white-collar $38.5 \%$ vs $60.1 \%$, respectively, $\mathrm{p}<0.001$ ) but not in marital status.

\section{Family history}

There were statistically significant differences among the $\mathrm{MI}<50, \mathrm{MI} \geq 50$, and no- $\mathrm{MI}<50$ groups in the presence of a family history of premature CVD in the first-degree relatives: $32.9 \%$ vs $9.6 \%(p<0.0001)$ and $32.9 \%$ vs $11.7 \%$ $(\mathrm{p}<0.0001)$, respectively (Table 3$)$. There were also statistically significant differences among the $\mathrm{MI}<50, \mathrm{MI} \geq$ 50 and no-MI $<50$ groups in the presence of a family history of premature CVD age involving the first- and second-degree relatives: $35.9 \%$ in the $\mathrm{MI}<50$ group vs $15.6 \%$ in the MI $\geq 50$ group $(p<0.0001)$ and $14.2 \%$ in the no-MI $<50$ group $(p<0.0001)$. Moreover, there were statistically significant differences between the studied groups in the family history of CVD events at every age within family members (the first- and the second-degree relatives): $65.4 \%$ in the $\mathrm{MI}<50$ group vs $47.6 \%$ in the MI $\geq 50$ group $(\mathrm{p}<0.0001)$ and $41.7 \%$ in the no-MI $<50$ group $(p<0.0001)$. 
Table 1 Clinical characteristics of the studied groups: patients with $\mathrm{Ml}$ aged $<50$ years $(\mathrm{Ml}<50)$, patients with $\mathrm{Ml}$ aged $\geq 50$ years $(\mathrm{MI} \geq 50)$ and young people without history of MI/CAD aged < 50 years (no-MI < 50); ns - not significant, ${ }^{a}$ - data for TG and glucose showed as median and 25-75th quartile (variables with non-normal distribution)

\begin{tabular}{|c|c|c|c|c|c|}
\hline & $\begin{array}{l}\mathrm{Ml}<50 \\
n=240\end{array}$ & $\begin{array}{l}\mathrm{Ml} \geq 50 \\
\mathrm{n}=240\end{array}$ & $\begin{array}{l}\mathrm{no}-\mathrm{Ml}<50 \\
\mathrm{n}=240\end{array}$ & $p$ value & $\mathrm{p}$ value \\
\hline & a & $\mathrm{b}$ & c & $a$ vs b & a vs C \\
\hline BMI (mean \pm SD) kg/m2 & $28.6 \pm 4.4$ & $27.6 \pm 4.0$ & $27.0 \pm 4.3$ & 0.012 & $<0.001$ \\
\hline $\begin{array}{l}\text { Smoking } \\
\text { n (\%) }\end{array}$ & $203(86.4)$ & $151(64.3)$ & $103(43.1)$ & $<0.001$ & $<0.001$ \\
\hline $\begin{array}{l}\text { Hypertension } \\
\text { n (\%) }\end{array}$ & $132(55.2)$ & $162(68.1)$ & $70(29.2)$ & $<0.001$ & $<0.001$ \\
\hline $\begin{array}{l}\text { Diabetes mellitus } \\
\text { n (\%) }\end{array}$ & $36(15.9)$ & $80(34.5)$ & $2(0.8)$ & $<0.001$ & $<0.001$ \\
\hline $\begin{array}{l}\text { Depression } \\
\text { n (\%) }\end{array}$ & $20(8.4)$ & $20(8.4)$ & $8(3.3)$ & ns & 0.018 \\
\hline Total cholesterol (mean \pm SD) mg/dL & $210.0 \pm 41.5$ & $197.7 \pm 50.4$ & $203.5 \pm 45.4$ & 0.006 & ns \\
\hline $\begin{array}{l}\mathrm{LDL} \\
(\mathrm{mean} \pm \mathrm{SD}) \mathrm{m} / \mathrm{dL}\end{array}$ & $132.4 \pm 39.5$ & $124.5 \pm 44.6$ & $123.3 \pm 36.5$ & ns & 0.049 \\
\hline $\begin{array}{l}\mathrm{HDL} \\
(\text { mean } \pm \mathrm{SD}) \mathrm{mg} / \mathrm{dL}\end{array}$ & $41.5 \pm 12.8$ & $46.7 \pm 13.9$ & $54.1 \pm 20.3$ & $<0.001$ & $<0.001$ \\
\hline $\begin{array}{l}\mathrm{TG}^{\mathrm{a}} \\
\text { (median, [25-75th] quartile) mg/dl }\end{array}$ & 145.5 [104.0-219.0] & $113.0[79.0-155.0]$ & $120.0[80.0-150.0]$ & $<0.001$ & $<0.001$ \\
\hline $\begin{array}{l}\text { Glucose }^{a} \\
\text { (median, [25-75th] quartile) mg/dl }\end{array}$ & $99.0[92.5-111.0]$ & $105[91.0-127.0]$ & $93.0[84.0-97.0]$ & 0.002 & $<0.001$ \\
\hline
\end{tabular}

Table 2 Socio-economic status of the studied groups: patients with $\mathrm{Ml}$ aged $<50$ years $(\mathrm{Ml}<50)$, patients with $\mathrm{Ml}$ aged $\geq 50$ years $(\mathrm{Ml} \geq 50)$ and young people without history of MI/CAD aged $<50$ years (no-Ml $<50$ ); ns - not significant

\begin{tabular}{|c|c|c|c|c|c|}
\hline & $\begin{array}{l}\mathrm{Ml}<50 \\
\mathrm{n}=240\end{array}$ & $\begin{array}{l}\mathrm{Ml} \geq 50 \\
\mathrm{n}=240\end{array}$ & $\begin{array}{l}\text { no-Ml }<50 \\
n=240\end{array}$ & $p$ value & $p$ value \\
\hline & a & $\mathrm{b}$ & c & a vs b & a vs C \\
\hline \multicolumn{6}{|l|}{ Education level } \\
\hline primary & $13(5.7)$ & $35(15.2)$ & $5(2.1)$ & 0.001 & $<0.001$ \\
\hline vocation & $75(32.7)$ & $51(22.2)$ & $28(11.9)$ & & \\
\hline secondary & $90(39.3)$ & $102(44.3)$ & $104(44.3)$ & & \\
\hline high & $51(22.3)$ & $42(18.3)$ & $98(41.7)$ & & \\
\hline \multicolumn{6}{|l|}{ Type of job } \\
\hline unemployed & $7(3.2)$ & $4(1.8)$ & $1(0.4)$ & $<0.001$ & $<0.001$ \\
\hline blue collar & $107(48.4)$ & $93(41.3)$ & $83(38.1)$ & & \\
\hline white collar & 85 (38.5) & $69(30.7)$ & $131(60.1)$ & & \\
\hline pensioner & $22(9.9)$ & $59(26.2)$ & $3(1.4)$ & & \\
\hline \multicolumn{6}{|l|}{ Marriage status } \\
\hline single & $42(18.5)$ & $20(8.6)$ & 39 (16.7) & $<0.001$ & ns \\
\hline married & $166(73.1)$ & $151(64.8)$ & 179 (76.8) & & \\
\hline divorced & $9(4.0)$ & $9(3.9)$ & $12(5.1)$ & & \\
\hline widowed & $10(4.4)$ & $53(22.7)$ & $3(1.3)$ & & \\
\hline
\end{tabular}

The statistically significant differences among the $\mathrm{MI}<$ $50, \mathrm{MI} \geq 50$ and no- $\mathrm{MI}<50$ groups also included the percentage of patients with $\geq 2$ affected relatives, including parents, children, siblings, siblings of parents, and grandparents, with a history of premature CVD events: $10.8 \%$ vs $2.9 \% \quad(p<0.0001)$ and $10.8 \%$ vs $3.7 \% \quad(\mathrm{p}<$ $0.0001)$, respectively; Fig. 1.

There were statistically significant differences in the age of the first episode of MI between patients without a family history of premature CVD and patients with 1 affected relative (56.6 vs 48.6 years, respectively, $p<$ $0.0001)$ and with $\geq 2$ affected first-degree relatives (56.6 vs 41.8 years, respectively, $p<0.0001$ ); Table 4 . These differences were also significant for first- and seconddegree relatives with premature CVD: 56.5 years for patients without affected relatives vs 50.7 for patients with 1 affected relative $(p=0.0003)$ and vs 47.0 years for patients with $\geq 2$ affected relatives $(p<0.0001)$. There were also statistically significant differences in the age of the first episode of MI among patients without a family history of CVD at any age and patients with 1 affected relative $(57.9$ vs 51.9 years, respectively, $\mathrm{p}<0.0001)$ and with $\geq 2$ affected first-degree relatives ( 57.9 vs 47.9 years, respectively; $\mathrm{p}<0.0001)$. These differences were also significant for first- and second-degree relatives with CVD event at any age: 58.1 years for patients without affected relatives vs 52.5 for patients with 1 affected relative ( $p=$ 0.0002 ) and vs 50.9 years for patients with $\geq 2$ affected relatives $(p=0.0005)$. There was a clear reversal 
Table 3 Family history of premature CVD events (MI/ischemic stroke in men aged $<55$ years and in women aged $<65$ years) in the studied groups: patients with $\mathrm{Ml}$ aged $<50$ years $(\mathrm{Ml}<50)$, patients with $\mathrm{Ml}$ aged $\mathrm{Ml} \geq 50$ years $(\mathrm{Ml} \geq 50)$ and and young people without history of MI/CAD aged $<50$ years (no-Ml $<50$ )

\begin{tabular}{|c|c|c|c|c|c|}
\hline & $\begin{array}{l}\mathrm{Ml}<50 \\
\mathrm{n}=240\end{array}$ & $\begin{array}{l}\mathrm{Ml} \geq 50 \\
\mathrm{n}=240\end{array}$ & $\begin{array}{l}\text { no-Ml } \\
<50 \\
n=240\end{array}$ & $p$ value & $p$ value \\
\hline & a & $b$ & $c$ & $a$ vs $b$ & a vs C \\
\hline Family history of $\mathrm{Ml} /$ stroke in the first-degree relatives - all; n (\%) & $79(32.9)$ & $23(9.6)$ & $28(11.7)$ & $<0.0001$ & $<0.0001$ \\
\hline Family history of $\mathrm{Ml} /$ stroke in the first-degree relatives - with $\geq 2$ affected; $\mathrm{n}(\%)$ & $9(3.7)$ & $1(0.4)$ & $3(1.2)$ & $<0.0001$ & $<0.0001$ \\
\hline Family history of $\mathrm{Ml} /$ stroke in the first- and the second- degree relatives - all; $\mathrm{n}(\%)$ & $84(35.9)$ & $36(15.6)$ & $34(14.2)$ & $<0.0001$ & $<0.0001$ \\
\hline Family history of MI/stroke in the first- and the second-degree relatives - with $\geq 2$ affected; $\mathrm{n}(\%)$ & $26(10.8)$ & $7(2.9)$ & $9(3.7)$ & $<0.0001$ & $<0.0001$ \\
\hline
\end{tabular}

a. First- and second-degree relatives with premature CVD events

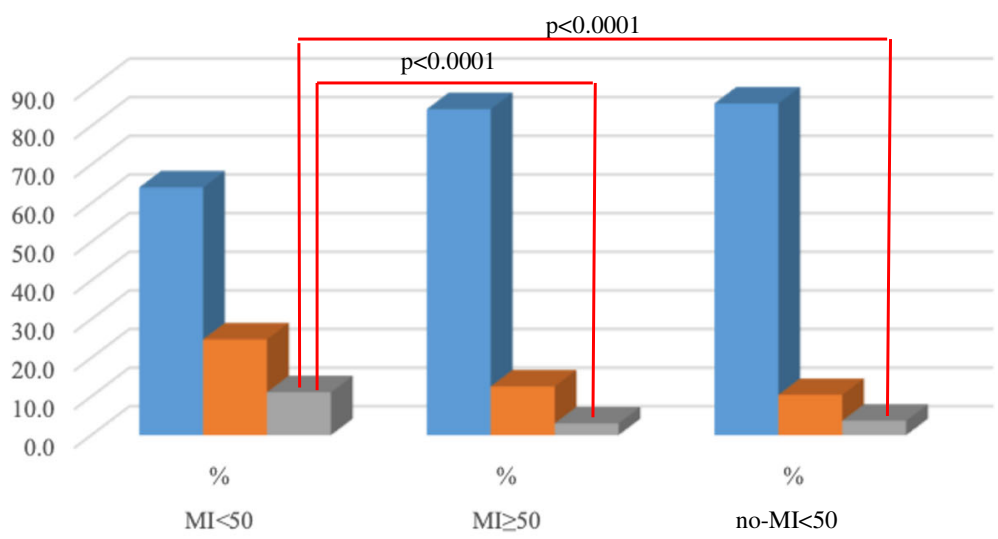

$\because 0 \quad \| 1 \quad \boxminus \geq 2$ relatives

b. First- and second-degree relatives with CVD events at every age $\mathrm{p}<0.0001$

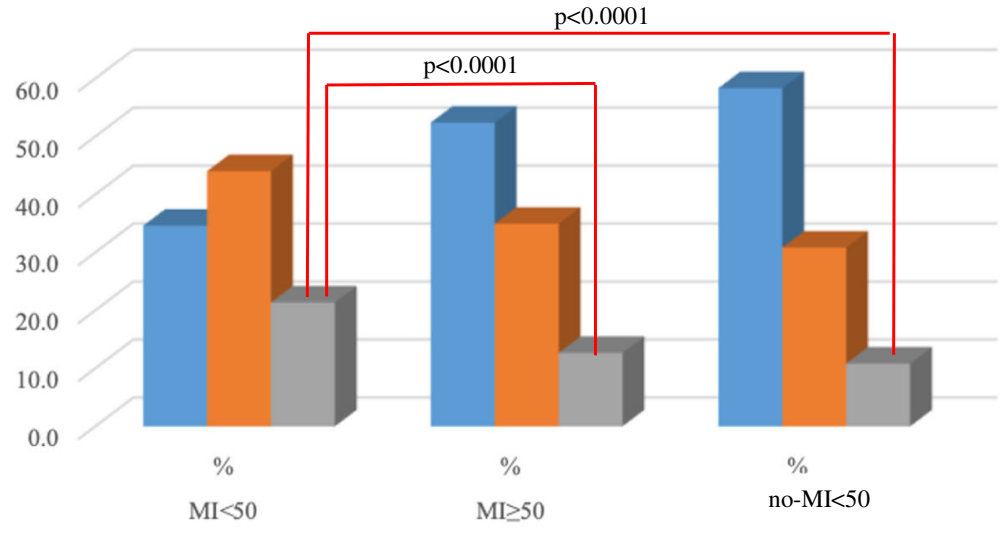

m $0=1 \quad$ m $\geq 2$ realtives

Fig. 1 Differences among the $\mathrm{Ml}<50, \mathrm{Ml} \geq 50$ and no-Ml $<50$ groups in the percentage of cases with 0,1 or $\geq 2$ first- and second-degree relatives with a history of CVD events: a family history of premature CVD events with $\geq 2$ affected relatives: $10.8 \%$ cases in the $\mathrm{Ml}<50 \mathrm{group}$ vs $2.9 \%$ cases in the $\mathrm{Ml} \geq 50$ group $(p<0.0001)$ and $10.8 \%$ cases in the $\mathrm{Ml}<50$ group vs $3.7 \%$ cases in the no-Ml $<50$ group $(p<0.0001)$; b family history of CVD events with $\geq 2$ affected relatives at every age: $21.4 \%$ cases in the $\mathrm{Ml}<50$ group vs $12.7 \%$ cases in the $\mathrm{Ml} \geq 50 \mathrm{group}$ ( $p<0.0001$ ) and $21.4 \%$ cases in the $\mathrm{Ml}<50$ group vs $10.8 \%$ cases in the no-Ml $<50$ group $(\mathrm{p}<0.0001)$ 
Table 4 Differences in the age of the first episode Ml among patients with 0, 1 and $\geq 2$ affected relatives with the history of premature CVD events and CVD events at any age

\begin{tabular}{|c|c|c|c|c|c|}
\hline Number of relatives: & 0 & 1 & $\geq 2$ & $\begin{array}{l}0 \text { vs } 1 \\
\text { Delta }[95 \% \mathrm{Cl}]\end{array}$ & $\begin{array}{l}0 \text { vs } \geq 2 \\
\text { Delta }[95 \% \mathrm{Cl}]\end{array}$ \\
\hline \multicolumn{6}{|l|}{ Family history of premature CVD events } \\
\hline $\begin{array}{l}\text { Patients with first-degree relatives affected } \\
\text { years } \pm S D(n)\end{array}$ & $\begin{array}{c}56.6 \pm 15.3 \\
(n=363)\end{array}$ & $\begin{array}{c}48.6 \pm 11.1 \\
(n=92)\end{array}$ & $\begin{array}{l}41.8 \pm 5.9 \\
(n=10)\end{array}$ & $8.0[4.0-12.0]$ & $14.8[4.0-25.7]$ \\
\hline$p$ & & & & $<0.0001$ & $<0.0001$ \\
\hline $\begin{array}{l}\text { Patients with first- and second degree relatives affected } \\
\text { years } \pm S D(n)\end{array}$ & $\begin{array}{c}56.5 \pm 15.3 \\
(n=344)\end{array}$ & $\begin{array}{l}50.7 \pm 12.6 \\
(n=87)\end{array}$ & $\begin{array}{l}47.0 \pm 10.9 \\
(n=32)\end{array}$ & $5.8[1.7-9.9]$ & $9.5[3.2-15.7]$ \\
\hline$p$ & & & & 0.0003 & $<0.0001$ \\
\hline \multicolumn{6}{|l|}{ Family history of CVD events at every age } \\
\hline $\begin{array}{l}\text { Patients with first-degree relatives affected } \\
\text { years } \pm S D(n)\end{array}$ & $\begin{array}{c}57.9 \pm 15.7 \\
(n=239)\end{array}$ & $\begin{array}{c}51.9 \pm 13.5 \\
(n=184)\end{array}$ & $\begin{array}{c}47.9 \pm 10.1 \\
(n-40)\end{array}$ & $6.0[2.7-9.3]$ & $10.0[4.2-15.8]$ \\
\hline$p$ & & & & $<0.0001$ & $<0.0001$ \\
\hline $\begin{array}{l}\text { Patients with first- and second degree relatives affected } \\
\text { years } \pm S D(n)\end{array}$ & $\begin{array}{l}58.1 \pm 15.7 \\
(n=201)\end{array}$ & $\begin{array}{l}52.5 \pm 13.5 \\
(n=183)\end{array}$ & $\begin{array}{c}50.9 \pm 13.6 \\
(n=79)\end{array}$ & $5.6[2.1-9.1]$ & $7.1[2.6-11.7]$ \\
\hline$p$ & & & & 0.0002 & 0.0005 \\
\hline
\end{tabular}

association between the age of the first episode MI and the number of first-degree relatives with a history of premature MI/stroke (Fig. 2).

When only MI, without ischemic stroke, was included in the family history, there were similar statistically significant differences in the age of the first episode MI among patients without a family history of MI, premature and at any age as well, with 1 affected relative and with $\geq 2$ affected relatives (Table in Supplementary Materials). There was also a significant reversal association between the age of the first episode MI and the number of affected relatives, including first-degree and first- and second degree relatives with a history of premature MI and MI at any age as well.

\section{Discussion}

In our study, there was a significantly higher incidence of a family history of premature CVD events in patients with $\mathrm{MI}$ at age $<50$ in comparison to patients with $\mathrm{MI}$ at age $\geq 50$ and to young people without history of MI/ CAD. A family history of early MI or stroke is a widely recognized risk factor for $\mathrm{MI}$ at a young age. In the Malmo Diet and Cancer Study, a family history of coronary heart disease (CHD) was associated with an incidence of CHD with a hazard ratio of 1.52 (95\% CI: 1.39-1.65), and only a small proportion of the family history effect was mediated by hypertension, hyperlipidaemia and diabetes [15].

Although the highest cardiovascular risk was associated with a maternal history at age $<50$ years and a paternal history at age $<55$ years, no substantial differences were seen between maternal and paternal positive CVD history [16]. In a Dutch cohort study, a particularly high incidence of CVD was revealed in people with parental onset of MI before age 70, with maternal history of MI before age 60 being the strongest predictor of CVD incidence [17].The offspring age of onset of CVD is significantly associated with both maternal and paternal age of CVD onset [18]. Nevertheless, data regarding the role of a family history of CVD that includes relatives other than parents or the number of affected family members are scarce.

In our study, there were significant differences among the $\mathrm{MI}<50, \mathrm{MI} \geq 50$ and no- $\mathrm{MI}<50$ groups in positive family history of CVD, and these differences involved not only the prevalence of premature CVD events restricted to parents but also such events in other first- and second-degree relatives. Moreover, there were statistically significant differences among the studied groups in the prevalence of CVD events at every age in family members (the first- and the second-degree relatives). A higher number of relatives with a positive history of CAD, including parents, children, siblings, siblings of parents and grandparents, was associated with a younger age of MI. The Danish Nationwide Cohort Study revealed that a history of MI in a combination of first- and seconddegree relatives increased risks 1.8 - to 7 -fold in middle-aged persons [19]. Moreover, it was shown in this study that younger age at MI in relatives was associated with higher MI risk.

Interestingly, there was a statistically significant reversal association between the age of the first episode of MI in our patients and the number of relatives with a history of premature $\mathrm{MI} /$ stroke, and this relationship was particularly evident in the analysis involving the first-degree relatives, but not exclusively. An Italian study revealed that 
a.

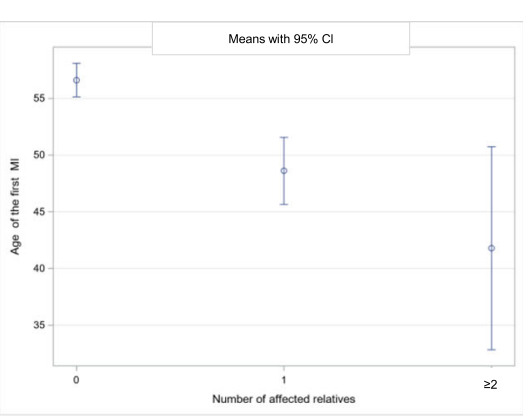

c.

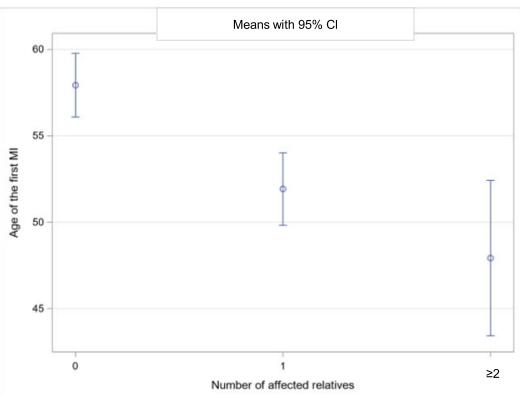

b.

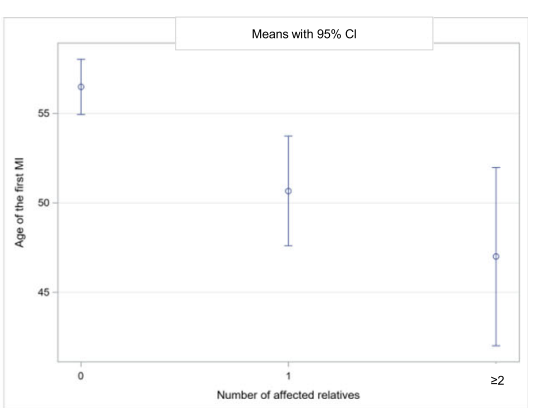

d.

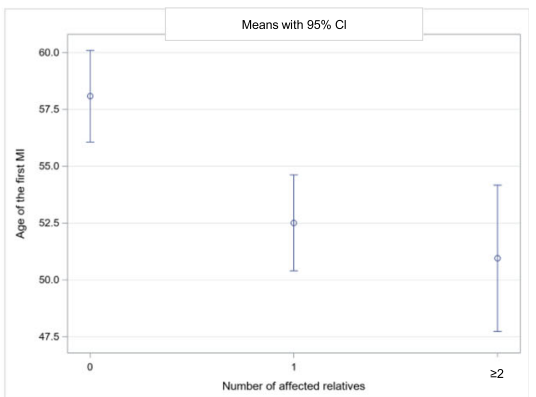

Fig. 2 Relationship between the age of the patient's first MI and the number of relatives with a history of CVD events. a Mean age with $95 \%$ Confidence Interval (Cl) of patients with first episode Ml: without a family history of premature CVD in first-degree relatives, with 1 affected relative and with $\geq 2$ affected relatives: 56.6 [55.1-58.1], 48.6 [45.7-51.6] and 41.8 [32.8-50.8] years, respectively. b Mean age with 95\% Cl of patients with first episode MI: without a family history of premature CVD in first- and second-degree relatives, with 1 affected relative and with $\geq 2$ affected first-degree relatives: 56.5 [55.0-58.0], 50.7 [47.6-53,7] and 47.0 [42.0-52.0] years, respectively. c Mean age with 95\% Cl of patients with first episode MI: without a family history of CVD at any age in first-degree relatives, with 1 affected relative and with $\geq 2$ affected relatives: 57.9 [56.1-59.8], 51.9 [49.8-54.0] and 47.9 [43.4-52.4] years, respectively. d Mean age with 95\% Cl of patients with first episode MI: without a family history of CVD at any age in first- and second-degree relatives, with 1 affected relative and with $\geq 2$ affected relatives: 58.1 [56.1-60.1], 52.5 [50.454.6] and 50.9 [47.7-54.2] years, respectively

being a relative (including parents, siblings and siblings of parents) of an early-onset MI patient confers an adjusted hazard ratio of 2.7 for such events [20]. There are also data indicating that early-onset hypertension in grandparents raises the risk for hypertension in grandchildren, even after adjusting for early-onset hypertension in parents and for lifestyle factors [21].

Among other risk factors, the prevalence of smoking, hypertension, DM as well as BMI, HDL, TG and glucose levels differ significantly between the $\mathrm{MI}<50$ group and both control groups $(\mathrm{MI} \geq 50$ and no-MI $<50$ ) in our study. Such findings are independent of region and patient ethnicity across the literature $[22,23]$. For instance, our data are in concordance with recently published data from New Zealand conducted in a more complex population, including Caucasians, Maori and Pacific islanders [24]. Although smoking, hyperlipidaemia and obesity are crucial among the risk factors for MI at a young age, there are some differences in their distribution between particular groups of patients [25, 26]. For example, the strongest predictor of ACS in women $\leq 45$ years of age was diabetes, with a 6-fold increase in risk [27]. Our study confirmed the significance of smoking, dyslipidaemia, obesity and carbohydrate metabolism disturbances as CAD risk factors.

The major limitation of our study was the relatively small number of patients; thus, the findings are difficult to apply to a larger, more diverse population. On the other hand, the high homogeneity of the groups, limited to the Polish population of Caucasian ethnicity, could be of value regarding the potential population and racial differences in the pathogenesis of CAD, particularly taking into account heritable risk factors. The control group of young healthy blood donors, usually more educated and more conscious of lifestyle than the general population, may not represent the community at large. Thus, the data coming from this group, including the prevalence of smoking, hypertension, DM, lipids levels or BMI may not be representative of the general population. On the other hand, the fact that donors stayed free from CAD until the age of 50, whereas our young patients suffered from MI before this age, enhances the role of lifestyle in CAD prevention.

\section{Conclusions}

This study revealed that a younger age of MI is associated with a higher number of relatives with a history of 
premature atherosclerosis. A family history of premature atherosclerosis involving not only first- but also seconddegree relatives seems to be a valuable factor in CAD risk evaluation in young people. The utility of these findings seems to be important for individual lifestyle change interventions as rational CVD prevention. Once a positive family history, particularly strengthened by such data, has been established, the health-care provider can emphasize the increased likelihood of MI at a young age as a strong incentive for patient-dedicated improvement in adherence to healthy lifestyles and medical regimens.

Family history of CVD is an effective indicator that one will have or develop key cardiovascular risk factors. Further analyses are required to determine whether a family history of premature CVD is associated with an increased likelihood of ACS at a young age independent of traditional cardiovascular risk factors.

\section{Supplementary information}

Supplementary information accompanies this paper at https://doi.org/10. 1186/s12872-020-01677-w.

Additional file 1: Table 1. Differences in the age of the first episode MI among patients with 0,1 and $>=2$ affected relatives with the history of premature $\mathrm{Ml}$ and $\mathrm{Ml}$ at any age.

\begin{abstract}
Abbreviations
ACS: Acute coronary syndrome; ADA: American Diabetes Association; AHA: American Heart Association; BMI: Body mass index; CAC: Coronary artery calcification; CAD: Coronary artery disease; CHD: Coronary heart disease; CVD: Cardiovascular disease; DBP: Diastolic blood pressure; HDL: High-density lipoprotein; LDL: Low-density lipoprotein; MI: Myocardial infarction; NSTEMI: Non-ST-elevation MI; SBP: Systolic blood pressure; STEMI: ST-elevation Ml; TG: Triglyceride; UA: Unstable angina; WHO: World Health Organization
\end{abstract}

\section{Acknowledgements}

Not applicable.

\section{Authors' contributions}

MA - conception and design of the study, data collection and analysis, interpretation of data, writing and revision of the manuscript. KNW - data collection and analysis. AM - data collection and analysis. AB - conception of the study, interpretation of data, revision of the manuscript. All authors have read and approved the manuscript.

\section{Funding}

This work was supported by the Centre of Postgraduate Medical Education grant no. 501-1-10-14-20; Warsaw, Poland.

It covers costs of biochemical analyses, statistical analyses, English language edition, and will cover the charge of publication in case of acceptance.

\section{Availability of data and materials}

The datasets used and/or analysed during the current study are available from the corresponding author on reasonable request.

\section{Ethics approval and consent to participate}

The participants gave written informed consent for participation in the study. The investigation conforms to the principles outlined in the Declaration of Helsinki, and the study protocol was approved by the Ethical Committee of the Centre of Postgraduate Medical Education.

\section{Consent for publication}

Not applicable.

\section{Competing interests}

The authors declare that they have no competing interests.

Received: 2 April 2020 Accepted: 20 August 2020

Published online: 11 September 2020

\section{References}

1. Virani SS, Alonso A, Benjamin EJ, Bittencourt MS, Callaway CW, Carson AP, et al. Heart Disease and Stroke Statistics-2020 Update: A Report From the American Heart Association. Circulation. 2020;141:9. https://doi.org/10.1161/ CIR.0000000000000757.

2. Wolfe MW, Vacek JL. Myocardial infarction in the young. Angiographic features and risk factor analysis of patients with myocardial infarction at or before the age of 35 years. Chest. 1988;94:5.

3. Deora S, Kumar T, Ramalingam R, Nanjappa Manjunath C. Demographic and angiographic profile in premature cases of acute coronary syndrome: analysis of 820 young patients from South India. Cardiovasc Diagn Ther. 2016;6(3). https://doi.org/10.21037/cdt.2016.03.05.

4. Trzeciak P, Wożakowska-Kapłon B, Niedziela J, Gierlotka M, Hawranek M, Lekston A, et al. Comparison of Inhospital and 12- and 36-month outcomes after acute coronary syndrome in men versus women $<40$ years (from the PL-ACS registry). Am J Cardiol. 2016;1 18:9. https://doi.org/10.1016/j.amjcard. 2016.07.067

5. Gierlotka M, Zdrojewski T, Wojtyniak B, Poloński L, Stokwiszewski J, Gąsior M et al. Incidence, treatment, in-hospital mortality and one-year outcomes of acute myocardial infarction in Poland in 2009-2012--nationwide AMI-PL database. Kardiol Pol. 2015;73:3. https://doi.org/10.5603/KP.a2014.0213.

6. Awad HH, McManus DD, Anderson FA Jr, Gore JM, Goldberg RJ. Young patients hospitalized with an acute coronary syndrome. Coron Artery Dis. 2013;24(1). https://doi.org/10.1097/MCA.0b013e32835b0bf7.

7. Ma Q, Wang J, Jin J, Gao M, Liu F, Zhou S, et al. Clinical characteristics and prognosis of acute coronary syndrome in young women and men: a systematic review and meta-analysis of prospective studies. Int J Cardiol. 2017;228. https://doi.org/10.1016/j.ijcard.2016.11.148.

8. Osadnik T, Pawlas N, Lonnie M, Osadnik K, Lejawa M, Wąołowska L, et al. Family history of premature coronary artery disease (P-CAD)-a nonmodifiable risk factor? Dietary patterns of young healthy offspring of P-CAD patients: a case-control study (MAGNETIC project). Nutrients. 2018;10. https://doi.org/10.3390/nu10101488.

9. Williams RR, Hunt SC, Heiss G, Province MA, Bensen JT, Higgins M, et al. Usefulness of cardiovascular family history data for population-based preventive medicine and medical research (the health family tree study and the NHLBI family heart study). Am J Cardiol. 2001;87:2.

10. Lloyd-Jones DM, Nam BH, D'Agostino RB Sr, Levy D, Murabito JM, Wang TJ, et al. Parental cardiovascular disease as a risk factor for cardiovascular disease in middle-aged adults: a prospective study of parents and offspring. JAMA. 2004;291:18.

11. Chow CK, Islam S, Bautista L, Rumboldt Z, Yusufali A, Xie C, et al. Parental history and myocardial infarction risk across the world: the INTERHEART study. J Am Coll Cardiol. 2011;57(5). https://doi.org/10.1016/j.jacc.2010.07. 054..

12. Ambroziak M, Kolanowska M, Bartoszewicz Z, Budaj A. Adiponectin gene variants and decreased adiponectin plasma levels are associated with the risk of myocardial infarction in young age. Gene. 2018;642. https://doi.org/ 10.1016/j.gene.2017.11.064.

13. Mancia G, Fagard R, Narkiewicz K, Redon J, Zanchetti A, Böhm M, et al. 2013 ESH/ESC Guidelines for the management of arterial hypertension: The Task Force for the management of arterial hypertension of the European Society of Hypertension (ESH) and of the European Society of Cardiology (ESC). Eur Heart J. 2013;34:7. https://doi.org/10.1097/01.hjh.0000431740.32696.cc.

14. American Diabetes Association. Standards of medical care in diabetes-2015 abridged for primary care providers. Clin Diabetes. 2015;33(2). https://doi. org/10.2337/diaclin.33.2.97.

15. Fritz J, Shiffman D, Melander O, Tada H, Ulmer H. Metabolic mediators of the effects of family history and genetic risk score on coronary heart disease-findings from the Malmö diet and Cancer study. J Am Heart Assoc. 2017;6(3). https://doi.org/10.1161/JAHA.116.005254.

16. Weiimans M, van der Graaf Y, Reitsma JB, Visseren FL. Paternal or maternal history of cardiovascular disease and the risk of cardiovascular disease in offspring. A systematic review and meta-analysis. Int J Cardiol. 2015;179. https://doi.org/10.1016/j.jicard.2014.11.017. 
17. van Dis I, Kromhout D, Boer JM, Geleijnse JM, Verschuren WM. Paternal and maternal history of myocardial infarction and cardiovascular diseases incidence in a Dutch cohort of middle-aged persons. PLoS One. 2011;6(12). https://doi.org/10.1371/journal.pone.0028697.

18. Allport SA, Kikah N, Abu Saif N, Ekokobe F, Atem FD. Parental age of onset of cardiovascular disease as a predictor for offspring age of onset of cardiovascular disease. PLoS One. 2016;11(12). https://doi.org/10.1371/ journal.pone.0163334.

19. Ranthe MF, Petersen JA, Bundgaard H, Wohlfahrt J, Melbye M, Boyd HA. A detailed family history of myocardial infarction and risk of myocardial infarction - a nationwide cohort study. PLoS One. 2015;(5):e0125896. https:// doi.org/10.1371/journal.pone.0125896.

20. Cipriani V, Mannucci PM, Ardissino D, Ferrario M, Corsini G, Merlini PA. Familial aggregation of early-onset myocardial infarction. Eur J Internal Med. 2010;21(6). https://doi.org/10.1016/.jejim.2010.07.017.

21. Niranen TJ, McCabe EL, Larson MG, Henglin M, Lakdawala NK, Vasan RS, et al. Risk for hypertension crosses generations in the community: a multigenerational cohort study. Eur Heart J. 2017;38(29). https://doi.org/10.1093/ eurheartj/ehx134.

22. Sinha SK, Krishna V, Thakur R, Kumar A, Mishra V, Jha MJ, et al. Acute myocardial infarction in very young adults: a clinical presentation, risk factors, hospital outcome index, and their angiographic characteristics in North India-AMIYA study. ARYA Atheroscler. 2017;13:2.

23. Lubiszewska B, Skóra E, Kruk M, Broda G, Ksiezycka E, Kurjata P, et al. Prevalence of classical risk factors in polish women with premature coronary artery disease. Kardiol Pol. 2010;68:9.

24. Matsis K, Holley A, Al-Sinan A, Matsis P, Larsen PD, Harding SA. Differing clinical characteristics between young and older patients presenting with myocardial infarction. Heart Lung Circ. 2017;26(6). https://doi.org/10.1016/j. hlc.2016.09.007.

25. Maroszyńska-Dmoch EM, Wożakowska-Kapłon B. Clinical and angiographic characteristics of coronary artery disease in young adults: a single Centre study. Kardiol Pol. 2016;74(4). https://doi.org/10.5603/KP.a2015.0178..

26. Soeiro Ade M, Fernandes FL, Soeiro MC, Serrano CV Jr, Oliveira MT Jr. Clinical characteristics and long-term progression of young patients with acute coronary syndrome in Brazil. Einstein (Sao Paulo). 2015;13(3). https:// doi.org/10.1590/S1679-45082015AO3381.

27. Bęćkowski M, Gierlotka M, Gąsior M, Poloński L, Zdrojewski T, Dąbrowski R, et al. Risk factors predisposing to acute coronary syndromes in young women $\leq 45$ years of age. Int J Cardiol. 2018;264. https://doi.org/10.1016/j. ijcard.2018.03.135.

\section{Publisher's Note}

Springer Nature remains neutral with regard to jurisdictional claims in published maps and institutional affiliations.

Ready to submit your research? Choose BMC and benefit from:

- fast, convenient online submission

- thorough peer review by experienced researchers in your field

- rapid publication on acceptance

- support for research data, including large and complex data types

- gold Open Access which fosters wider collaboration and increased citations

- maximum visibility for your research: over $100 \mathrm{M}$ website views per year

At $\mathrm{BMC}$, research is always in progress.

Learn more biomedcentral.com/submissions 